viz., that in the museum of St. George's Hospital, which weighed over four pounds, and where no cause of obstruction was discernible; but it is more constantly the case in such hypertrophies, for instance, as that of the thyroid gland, a part which is frequently the seat of new growth, as distinguished from enlargement.

Also, it is most strikingly true, that those parts which are subject to occasional or periodical enlargement, or on which the overgrowth is consequent to change, perhaps functional, in some other organ. Take, for instance, the uterus and mammary gland in women.

Whatever the mechanism may be, there is no doubt some mechanism hy which these parts are especially disposed to abnormally rapid nutrition and activity of growth under particular circumstances. This machinery will, we know, from time to time, act blindly. The uterus will enlarge around a tumour, or a mole, and finally contract upon it, as in parturition; and the mammæ will often enlarge sympathetically with various affections of the uterus, not necessarily with pregnancy. (Lee's Lictures on Aidzwifery, p. 169.) Can we doubt that some disordered action of this mechanism is an important factor in the production of tumours in these parts, and that the remarkable frequency of new srowths in the mammx and uterus is partly thus to be explained?

[To be continued.]

\section{CLINICAL LECTURE on}

\section{DISEASES OF THE EAR IN RELATION TO PYÆMIA AND CEREBRAL ABSCESS. Delivered at St. Georse's Ilospital.}

By W. B. DALBY, F.R.C.S., M.B.Cantab., Aural Surgeon to the Hospital.

Lintuemen,--On December 30 h, I was requested by Dr. Wadhan to see a boy, C. H., io years old, who was admitted under him into the King's Ward on the day before, and who, among other things, was suffering from a discharge from the left ear; and it is in consequence of the important part which the ear-affection played in causing the boy's death, that I have the privilege of delivering the clinical lecture to-day. The child had been sent into the hospital, supposed to be suffering from ague, and I obtained from his mother the following account of his illness. Three months ago, he was in good health, when, during an ordinary cold, he became deaf in the left ear. He continued pretty well, with the exception of the impaired hearing, until two weeks before his admission, and at that time he had an attack of pain in the left ear, which, lasting for between two and three days, was succeeded by a purulent discharge, and, with the appearance of the discharge, complete relief from the pain. Three days subsequently to this, he had a shivering fit, and this was repeated each day for a week. Shortly after the first shivering, the pain in the ear returned, and very soon involved the side of the head; and he suffered so much in this respect, that he was put to hed, and kept there until his removal to the hospital. When I saw him, there was a purulent discharge from the left ear; the tympanic membrane was ulcerated away; he was very deaf on that side; he was suffering from a good deal of pain in the head, especially in the neighbourhood of the ear; there was extreme tenderness, on deep pressure, over the mastoid process; some redness, but no swelling; no tenderness in the course of the carotid sheath. Pulse, $\mathbf{1 2 8}$; temperature, 99.8. He had a dry, brown tongue. The nurse said he had not slept. He lay maning with his hand to his head, and had all the appearance of a patient suffering from blood-poisoning. He had an occasional dry cough, fut no abnormal sounds in the chest had been detected, except that, at the apex of the right lung, the respiration was harsh and the voice sounds increased.

On January Ist, the pain on the left side of the head was so severe, and the tenderness over the mastoid process so much increased, that I believed it probable that the inflammation had spread from the tympanum to the mastoid cells, and that possibly the presence of pus in these cavities might be aggravating the symptoms. This, however, was uncertain, insomuch as there was no cedema, nor swelling of the integuments immediately over the bone. Notwithstanding these negative signs, I made an incision over the mastoid process, half an inch from where the ear joins the head. The periosteum and the bone beneath were healthy. I then made a small opening into the bone, the probe freely entering into the cells, in the direction of the tympanum, to the depth of an inch. No discharge of pus followed this, nor subsequently. Although, on the day afterwards, the pain in the head was somewhat better, his general condition remained unchanged. On the 7 th, he had more shivering and an occasional cough. Not to ?well any longer in recounting this case, he now developed all the signs of fluid in the right pleura, and, at no time losing consciousness, he died on the 17 th.

At the post mortem examination, the chief points which call for remark are, that the anterior two-thirds of the right pleura were filled with pus containing flakes of lymph ; in the lower lobes of the right lung were several abscesses (none of them near the surface of the lung), with ragged walls filled with foul pus. The surface of the brain was somewhat congested, but otherwise it was healthy. There was no thrombus of the lateral sinus. Between the roof of the left tympanum and the clura mater was a small quantity of tough lymph. Here is the temporal bone. You will notice that the tympanic membrane is absent; the cavity of the tympanum is full of pus, the ossicles are necrosed and lie loose; the roof of the tympanum is carious on either surface, and the roughness on the cranial surface extends back to the sulcus for the lateral sinus.

This boy died from pyæmia, and the starting-point of the disease was a suppurating surface in the cavity of the tympanum. I will just ask you to notice how an apparently trifing disorder may terminate fatally. The order of events is somewhat in this fashion. The boy has an ordinary cold ; the catarrhal condition of the nares is continued up the left Eustachian tube into the tympanum; the tube becomes obstructed, and the tympanum distended with mucus, so the conduction of sound is interfered with. In the usual course of events, if this were not treated, the mucus would become inspissated, leaving behind more or less deafness ; instead of this, by and by, inflammatory action prcceeds another step; the non-purulent catarrh becomes purulent; the tympanum becomes full of pus; this makes for itself a way of escape by ulceration through the tympanic membrane; there is a discharge from the ear; the cavity of the tympanum is a suppurating surface; this is followed by caries of the bone, purulent absorption, pyxmic deposit, and death. More usual than pyæemia, as an immediate cause of death in cases of disease of the tympanum terminating fatally, is cerebral abscess. Out of seventy-six cases of this latter affection recorded by Sir W. Gull and Dr. Sutton (in Reynolds's System of Medicine), twenty-eight, or a little more than one-third, arose from ear-disease The various appearances generally met with (and there are accounts of many in the post mortem books) are, pus between the cranial surface of the temporal bone and the dura mater, pus in the arachnoid cavity, abscess or abscesses in the cerebrum or cerebellum, and plugging of the lateral sinus (thrombosis). In these temporal bones from the museum, with most of them, the roof of the tympanum, you observe, is carious, as in the case before us. In one fatal case which I saw in the hospital in 1866 , the disease had extended from the tympanum through the labyrinth and the internal auditory meatus. In other instances (and these are the most uncommon), the suppuration has been confined to the mastoid cells, the tympanic cavity remaining healthy, and the tympanic membrane entire. Where the seat of abscess is in the cerebellum, it is most usual to find the mastoid process diseased. And now, to go back again to the early history of these cases, and the way in which the ear-trouble may begin. Of all the causes which give rise to suppuration in the tympanum, scarlet fever and the other exanthemata are the most frequent; and next, perhaps, what is spoken of as idiopathic inflammation of this cavity, the meaning of this term (idiopathic), so far as I know, being, that it occurs without our knowing why or how. We meet with it as an affection characterised by severe pain in the ear, attended with more or less feverish symptoms, and succeeded by a rapid cessation of the pain and rupture of the tympanic membrane, as shown by its characteristic appearance, and a purulent discharge from the ear. Again, a non-purulent catarrh may, as in the case of this boy, merge into the purulent form. Lastly, and of this I have seen several cases, suppuration may be set up in the tympanum by an accidental rupture of the tympanic membrane. The first serious symptom with patients who die in the way we are considering is very generally a rigor ; and this, when it often recurs, sometimes leads the friends of the patients to suspect that they are suffering from ague (as in the present case); but you will find that patients who are the subjects of cerebral abscess and meningitis, when once what we speak of as head-symptoms have set in, will exhibit a considerable variety of symptoms. Some are furiously delirious, others have convulsions, and others have epileptiform fits. I have seen all of these, but in most of the cases they have laid in a half stupid state for some days, evidently suffering from pain in the head, moaning sometimes, until they have become comatose and died. A few days generally suffice for the termination of these cases; but this varies very much, and one case has been recorded (in the article I have mentioned) in which the patient lingered for fifty-three days.

And now, gentlemen, there are some points in comnection with this class of cases which are well worthy of your careful consideration. The first of these is to recognise the condition under which your patient is 
suffering, and, by taking note of the condition of the ear, to be able to trace the clisease to its true source, and so you will then be enabled to estimate pretty accurately the gravity of the case and the probable (I was going to say inevitable) termination. Other questions are, Is there any precaution which should be taken in the instances of persons suffering from a discharge from the ear, with a perforate tympanic membrane? Is there any period of the affection at which surgical interference may rescue them from a position of great peril? I will first reply to the last question. During the past four years, I have had occasion to see two cases, both of which died from cerebral abscess, under very similar conditions as regards the ear. In the case of each, on examination of the ear, a polypus was found to be preventing the escape of pus from the tympanum. The tympanic membrane was (as it generally is) ulcerated away, and, upon removing the polypus, there escaped a quantity of fotid pus, which had, by the presence of the growth, been kept pent up in the tympanum. One can hardly resist the conviction that, if the growth had been removed and eradicated before the occurrence of the headsymptoms, a fatal issue might have been averted. The conviction, too, is strengthened upon recalling to my mind many instances where constantly recurring pains in the head have disappeared after the removal of a polypus. Once more, let me call your attention to the layer of tough lymph overlying the cranial surface of the bone. It seems as if this product of inflammation had arrested the further advance of disease brainwards; indeed, that it is what I might speak of as preservative lymph. Again and again, we find persons with a perforation in the tympanic membrane suffering from pains in the head, which, after lasting for several days, pass off, leaving no evil consequences behind. May they not possibly have escaped further trouble by a provision similar to what we see here? Although, in the case of this boy, the bone was carious, it is by no means always so in fatal examples of brain-abscess. Again, it cannot be too much insisted upon that, whenever there is severe deep-seated pain in the mastoid process, with extreme tenderness on firm pressure, and swelling of the integument over the bone, an incision should be made down to the bone. If this be followed by an escape of pus, well and good; but, if the symptoms be urgent, an opening should be made into the mastoid cells. Although it was done with this boy, without any benefit (for there was no pus in the cells), a solitary case is of no use for guidance in all others. Redness, considerable swelling, and œdema will indicate plainly enough the presence of pus ; but it is quite possible for there to be pus in the mastoid cells, setting up great irritation, and ominous head-symptoms, without such external signs. The mastoid cells have, you know, been perforated on several occasions, and, in some, with the happiest results. I was very much struck with a case in which I did this early in last year. The symptoms were very urgent, and, what is rare, the tympanic membrane was entire. The seat of inflammation was exclusively the mastoid cells ; there was no perceptible swelling ; but, on perforating the bone, a few drops of foetid pus escaped, and the man had not a bad symptom afterwards.

In conclusion, I would propose for your consideration the question, whether, in all cases of a perforation of the tympanic membrane at tended with a purulent discharge from the ear, common sense and surgical instinct do not alike suggest that the ear should be kept scrupulously free from secretion, and some cleansing astringent be applied to the suppurating surface ; and, again, after all, may we not regard the fatal issue of such cases as often accidents of disease (so to speak), when we reflect how very large a number of people pass many years of their life with a purulent discharge from the ear and a perforation of the tympanic membrane, while, of the comparative few who die of pyæmia or cerebral abscess, it is only in the instances I have named that an extra exciting cause can be pointed to as leading immediately to such an issue ?

\section{ON HEAT, A POWER OF MOTION IN THE LIVING BODY IN HEALTH AND DISEASE.}

\section{By WILLIAM MARCET, M.D., F.R.S., Nice.}

HEAT is a mode of motion and a power for change in the mineral kingdom; and the same remark must equally apply to the living animal body. We consider heat as the result of a vibration or motion of matter, which may be developed by friction, percussion, or compression ; its most important seat of formation being the sun. When matter becomes heated, a portion of the heat thus taken up is tangible, either to our feelings or to the thermometer, and in a fit state for performing actual work, when it is known as potential; another portion of the heat, being employed in pushing asunder the atoms of matter, becomes absorbed, is not sensible to the thermometer, and remains in the latent or powerless condition until given out in the potential form. Water, for instance, whose capacity for heat is great, may feel cold to the touch, and yet have in store a considerable amount of heat fit for work under those conditions which promote the evolution of this heat in the tangible and active state.

Dr. Tyndall, whose highly instructive and interesting work on Heat a Mode of Motion has suggested to me the remarks embodied in the present communication, gives an excellent illustration of the passage of heat from the latent condition into the tangible or potential state. $\mathrm{He}$ takes a supersaturated solution of sulphate of soda, prepared by allowing to cool undisturbed a solution of this substance in hot water holding a greater quantity of the salt than the water could contain when cold, except if kept in a state of perfect repose; on dropping into the cold solution a crystal of sulphate of soda, crystallisation immediately sets in. Shortly afterwards, a thermo-electric pile, placed in communication with the fluid, will indicate heat by the deflecting action on the needle of a galvanometer. This heat is precisely the same in amount as that which the crystals had abstracted from the hot water in order to dissolve, and it is given out on the crystals forming afresh.

Now, all vegetables absorb heat during growth; this heat is derived from the sun, but, being used up in the work required for the nutrition of the plant, it remains latent or concealed within the substance of the tissues. When a $\log$ of wood is burnt in our fireplace, the amount of heat it yields is precisely the same as that which it had originally taken from the sun for the work necessary to its growth, so that the heat given out in an hour from a piece of burning wood may have taken years to accumulate within it

Heat, consequently, is a power which becomes bottled up, if I may so express it, by the object on which this power has been exerted ; it is equally present in our food, whose carbon and hydrogen yield it in a definite quantity when their attraction for oxygen comes into play. Heat thus liberated becomes potential, and must expend its energy in one way or another. It is to this phenomenon that the temperature of living animals is due; this heat exerts its power partly by effecting the various functional changes which are constantly in progress in the body, partly by ministering to muscular movement. Consequently, the various processes on which depend the maintenance of life are a source both of liberation and of consumption of heat; the liberation being due to oxidation, the consumption to the work the heat has to perform in the body - a phenomenon necessarily attended with cooling. In addition to this production of cold, temperature is abstracted by radiation from the body, which must keep drawing upon food for a continued supply of heat. It follows that food has two great objects to secure-that of yielding material to be transformed into tissues, and that of imparting heat, and consequently power, for the due performance of the functions of life.

There is, however, another source of animal heat, which must be more effectual than is usually considered to be the case, namely, the direct action of the sun. In tropical climates, this means undoubtedly acts an important part towards the performance of the animal functions ; indeed, heat cannot be derived in sufficient amount from food where a pound or two of rice are sufficient to keep up life, as we find it the case with the natives in Bengal. Again, I need not allude to the frequent necessity of using artificial heat shortly after birth, when the body can hardly maintain its own temperature.

A certain class of invalids proceed every year, about the beginning of November, to the shores of the Mediterranean, and various stations in Egypt and Africa, there to enjoy a mild winter with a bright warm sun, and, not unfrequently, a succession of fine days lasting for two or three months, or even longer, with hardly any interruption. Here they can walk and drive out every day, even in the middle of winter, which is cheated out of its fogs and drizzling rain, its cold, cutting winds, and snowstorms. But, if a weakened state of health be benefited by such a change of climate, I may be allowed to doubt whether healthy and robust persons will be the better for wintering in the sunny south. It must be remembered that the succession of the seasons in the northern latitudes is in many respects an advantage in a sanitary point of view. In winter, the functions of the body undergo a kind of repose or rest there is less heat and light, and consequently less activity, in the vital phenomena; this we are unconscious of, nevertheless there can be little doubt that it is so. The hibernation of certain animals is due to a torpid condition of all their functions; again, when the air is very cold, and the body exhausted by muscular exercise, or weakened from want of food, a feeling of drowsiness and numbness creeps on, clearly indicating a failure of vital power, which can only be restored by the external application of warmth and the administration of fool. After the disappearance of snow and ice, when, in the early spring, nature appears to waken afresh and rejoice in the bright warm rays of the sun, human beings and animals are equally conscious of a renewal of life, energy, and strength. Those who winter in the south, in search of a temperature which the weakened functions of their body may require, must recollect 